\title{
The Role of a Protean Career in High Performance
}

\author{
Ali Adnan Hasan, Pro. Dr. Ali Hasoon Altaee
}

DOI: $10.37648 / \mathrm{ijrssh} . v 10 \mathrm{i} 04.016$

Received:20 th September, 2020; Accepted:19 ${ }^{\text {th }}$ October, 2020; Published:22nd October, 2020

\begin{abstract}
The current research aims, to investigate the relationship between protean career and high performance in some colleges (Engineering, Sciences, Ibn Al-Haytham for Sciences) at University of Baghdad. The research also tries to provide consolidated recommendations that enhance to strengthening practice and adoption of the two variables in the observed colleges. The exploratory approach was adopted to analyze the date of the research based on out coming benefits for faculties, members, and college society. The research sample involved some professors at Engineering, Sciences, and Ibn Al-Haytham for Sciences colleges, the 55 questions of the conducted questionnaire was distributed to (313) professors. The valid questionnaires were (304) respondents who filled the 55 questions correctly. Personal interviews and observations were supported tools in order to enrich the ultimate resulted. The (normal distribution test, confirmatory factor analysis, building variables models, the arithmetic mean, percentages, standard deviation, relative importance, coefficient of variation, coefficient Pearson Correlation, Simple Regression Coefficient, Path Analysis, Sobel's Test, Aroian's Test, and Godman's Test) in the (SMART PLS V.23, SPSS V.23) programs utilized to test the research main and sub hypotheses. The most prominent result is correlations and influence relations between two variables of the research were positive and significant, some recommendations and suggestions were included at the end of the research to improve performance dramatically.
\end{abstract}

Keywords: Protean career; high performance; science colleges

\section{First: Research problem}

There is a clear, perceived and diagnosed gap between the current state of performance at the university and the performance it wants to reach. Therefore, the two researchers see the need for the university to realize the variable of the protean career path of individuals and its active role in the face of the size of the challenges and difficulties they face in the current period and the reflection of the impact of this variable on high performance, and thus the features of the field problem are evident by framing it within the following questions:

- What is the level of interest in the research variables (protean career path, high performance) in the faculties of the researched university, and which of these variables receive attention and adoption?

- What is the type and direction of the relationship between the dimensions of the protean career path and high performance and their nature?

- What is the effect of the dimensions of the protean career path in high performance on the viewpoint of the individuals (the research sample) in the faculties of the researched university?

\section{Second: The importance of research}

The importance of research in the applied aspect can be explained through the following points: 
A- The current research represents a scientific and practical contribution to determine the level of influence of research variables (the protean career path in high performance) at the University of Baghdad (the three colleges researched).

B- The importance of field research is evident in choosing the educational sector, which represents one of the important sectors in the country, as it provides services of scientific value to individuals, as well as its role in scientifically qualifying individuals, and then providing some solutions by analyzing and interpreting data with a variety of statistical means for the benefit of specially researched colleges and the university generally.

C- Establishing an administrative culture in the research sample in the researched colleges about the importance of the protean career path and its role in the high performance of the researched faculties.

D - The research, through the expected results, contributes to providing solutions that help in enhancing high performance through the basic features or components of the protean career path in creating a kind of motivation towards achieving success in the faculties researched.

\section{Third: Research Objectives}

The current research seeks to achieve a set of goals, as this modest scientific contribution is in harmony with the interests shown by administrative thought. Accordingly, the current research aspires to achieve the following objectives:

1. Presenting and presenting the most important theoretical and philosophical concepts and deriving the intellectual implications of the current research variables (protean career path, high performance) by reviewing the most important scientific propositions related to those topics in administrative thought in a serious attempt to provide the appropriate answers to the colleges. The research sample will be followed by public organizations.

2. Providing an integrated cognitive framework for the basic research variables represented by the protean career path and high performance at the individual level by reviewing the most important scientific proposals on these topics in the field of management, and working to provide appropriate answers about the motives of the intellectual problem and questions of the field problem of the current research.

3. Diagnosing the level of each of the protean career path and high performance in the faculties of the researched university.

\section{Fourth: Search Sample}

The sample was adopted randomly, and it is one of the probability sampling methods used in selecting the appropriate research sample, after the two researchers inventoried the number of teaching staff working in it, because he wanted to know the level of practice and availability of the protean career path and high performance, according to the college records and according to the position of the owners that the researchers looked at from (Human Resources Department) in the Presidency of the University, and through the lists that included preparing the community, it was fully enumerated (1313) teaching, and after the researchers resorted to applying the Thomson equation for small samples, the sample whose opinions should be investigated became (298) views, in addition to adding (15) observations to exceed the sampling error (5\%), and thus the actual number ready for the questionnaire to be distributed is (313), and it has been fully distributed to them, and retrieving (304) questionnaires valid for analysis and dispersal, without any defect in exclusion.

\section{Fifth: Approved statistical methods}

For the purpose of analyzing the data of the research and testing hypotheses, the use of a set of programs are ready (SPSS V.26, SMART PLS V.3.3.8), and in this regard has been used a set of statistical tools, which were divided into the following totals: (Alpha-Cronbach): (Spearman) (Split-Half).(Kolmogorov-Smirnov).

\section{THE THEORETICAL SIDE}

\section{First: Protean Career}

\section{The concept of a protean career path}

The word "protean" is taken from the Greek word Proteus, which symbolizes the Greek myth of the god Proteus, who had a strange ability to change shapes to 
avoid threats (Haber \& Bertone, 2016: 1). The concept of a protean career path was introduced by Hall, 1976) as a response to changing career paths that contain more freedom and growth (Gubler, 2014: 23).

The protean paths have been described as involving greater mobility, an integrated and holistic perspective on life, as well as developmental progress (Sultana\& Malik, 2019:1)

The protean career path includes learning cycles that are repeated every few years and contribute to improving performance. In addition, individuals with a volatile orientation have a strong motivation to learn (Briscoe \& Hall, 2006: 4).

The protean career path also refers in theoretical terms to individuals who assume or control the responsibility of their career and adapt to environmental changes (DiRenzo \& Greenhaus, 2011: 567) and it also means self-reliance in formulating career path plans and decisions related to them, looking for changes and acting according to them. (Enache \& et al, 2012: 2).

Or it aims to provide an effective and independent role for employees in managing and developing their own career path that helps them achieve their personal goals (Cao \& et al, 2013: 58). The protean path was also defined as a job in which the individual faces greater responsibility for his choices and career opportunities, and the individual values freedom and self-growth and determines career success in terms of psychological factors (such as job satisfaction, self-fulfillment, and personal achievement) compared to the traditional job (Hall \& Chandler, 2005: 176).

From the foregoing, researchers can find an appropriate definition that fits with the trends of the protean career path "as one of the modern career paths produced by the rapidly changing environment and which focuses on the job led by the individual and not the organization based on internal motives and values in which the individual places self-realization and psychological success above the concerns and rules that are Its source is outside the individual.

\section{Dimensions of protean Career Path}

Since (Briscoe et al, 2006) published a study to validate the first recommendation of the PCO scale, called the
Volatile Career Path Scale (PCAS), this scale consists of two main dimensions, namely: self-directed and values driven as is. It is still adopted and has become the most widely used scale among its various strengths. (Briscoe et al., 2006,15) Therefore, it was adopted by the researchers for the purposes of this research if the researchers did not find other approved and well-tested measures, and the following is an explanation of these two dimensions within the scale:

a. Self-direction: The self-direction dimension represents the independent role that the individual plays in enhancing his career development and it is considered an important concept in the literature because it is important to the individual's career success, especially the success of the self-directed career path (King, 2004: 126).

Self-direction is defined by the extent to which the individual realizes that he has the ability to pursue career progression, i.e. the focus is on the individual, and not on the organization, in taking responsibility for his career path because it is a contract between the individual with himself, and not between him and the organization as it relates to the basic need for independence. It ultimately leads to the realization that individuals have a lot of career opportunities inside and outside the current organization (Sirén et al., 2018: 4).

B. values driven: The ethical orientation-based dimension means that the generation and evaluation of career goals is based on the internal values of the individual rather than other standards and values (Hall, 2004: 5), and to allow the self to lead by personal values requires prior self-knowledge and also requires identifying values that are truly relevant to the individual. Through a comprehensive internal reflection (Kopelman, et al, 2012: 163), the individual here depends on the personal concept of success in his career as well as the consolidation of personal values during work because they seek to benefit from their experiences at work as well as benefit from the experiences of others such as family, friends and the organization They view the organization as a place where they promote their values and principles and express their pride in their culture (Enache et al., 2012: 4) 
(IJRSSH) 2020, Vol. No. 10, Issue No. IV, Oct-Dec

\section{Second: High Performance}

\section{The concept of high performance}

High performance indicates performance that exceeds normal performance in addition to being a series of distinguished performance, meaning that every action or activity enhances and strengthens achievement within the organization and includes many of the work forces that constitute its structure (McGregor, 1999: 279), and the system of high performance work is defined as a series of Policies and consensus on a high degree within the human resource management of the organization in order to serve the strategic objectives of the organization (Alotaibi et al, 2015: 117).

Researchers can set a procedural definition of high performance, that it is the highest level of performance that the organization can reach and to the extent that it enables it to exceed or equal levels of performance of other organizations in the same field of its work.

\section{High performance dimensions}

The dimensions that were relied upon in this research are those presented by (De Waal, 2008,2010), as these dimensions have been sufficiently tested in the public sector as the global survey collected data on (623) public organizations, and therefore the statistical analysis of data and high performance factors The five derived from this can be considered relevant to public organizations, as the research of high performance provides general managers an insight into the factors and characteristics of high performance organizations that ultimately lead to the creation of a high performance government organization D. Waal, 2010: 89). The following is an explanation of these dimensions:

A. Management Quality - In this aspect HPO managers focus on encouraging belief and trust in one another. That is, they value loyalty, live with integrity, treat their employees with respect and maintain individual relationships with them, and HPO managers adhere to a strong set of principles and standards. They are supportive and help employees in achieving their results, as well as holding them accountable for these results. HPO managers serve as a role model for the rest of the organization (the role model) (A. de Waal \& Sultan, 2012: 216).
e-ISSN: 2249-4642, p-ISSN: 2454-4671

B. Openness and work orientation - at (HPO) management values employee opinion by frequently seeking dialogue with them and their involvement in all important business and organizational processes. HPO allows trial and error by allowing employees to take risks, be willing to take risks themselves, and see mistakes as an opportunity to learn. In this regard, management welcomes and stimulates change through the continuous pursuit of renewal, developing dynamic managerial capabilities to enhance flexibility and personal participation in change activities. People in HPO spend a lot of time in dialogue, knowledge sharing and learning in order to get new ideas to improve their work and make the entire organization performance driven (D. Waal, 2010: 86).

T. Long-term orientation - long-term commitment is more important than short-term gain (HPO). Stakeholders benefit from the organization in the longterm as per the long-term orientation, and they are confident that the organization maintains long-term mutually beneficial relationships with them. (HPO) managers are committed to the organization, and new positions are filled from within the organization. HPO is a safe workplace where people feel free to contribute the best they can (de Waal et al. 2014: 32).

D. Continuous improvement and renewal - (HPO) assumes a unique strategy that makes the organization stand out in this aspect as it responds to market developments through the continuous innovation of its products and services, thus finding new sources of competitive advantage. (HPO) ensures that it maintains core capabilities within the organization and that it outsource non-core capabilities (de Waal \& Chachage, 2011: 83).

C. Workforce Quality - HPO personnel should be flexible and as they are trained (either formally or on the job) to achieve exceptional results. As a team, these forces are diverse and thus complementary to each other so that they can deal with a variety of issues and suggest additional alternative ideas for improvement (Waal \& Mulimbika, 2017: 3). 
THE PRACTICAL FRAMEWORK OF RESEARCH

First: Results of the test of normal distribution of data:
Table (1) shows the results of the normal distribution, and from these results the researchers conclude that the data of the variables are normally distributed, and it is then possible to resort to the use of parameterized statistical methods.

Table (1) tests for the normal distribution of the data of the research variables and their dimensions

\begin{tabular}{|l|c|c|c|c|c|c|}
\hline Variables & skewness & kurtosis & $\begin{array}{l}\text { Number of } \\
\text { paragraphs }\end{array}$ & $\begin{array}{l}\text { Standard } \\
\text { D value }\end{array}$ & Statistics & $\begin{array}{l}\text { Degree of } \\
\text { freedom }\end{array}$ \\
\hline The protean career path & -0.401 & -0.288 & 9 & 0.078 & 0.099 & \\
\hline values driven & 0.269 & -0.722 & 5 & 0.078 & 0.142 \\
\hline Self-direction & -0.765 & 0.806 & 4 & 0.078 & 0.126 \\
\hline High performance & -0.306 & -1.065 & 23 & 0.078 & 0.134 & \multirow{2}{*}{304} \\
\hline continuous improvement & -0.174 & -1.078 & 5 & 0.078 & 0.123 & \\
\hline Openness and work orientation & -0.519 & -0.929 & 5 & 0.078 & 0.143 & \\
\hline Management quality & -0.179 & 0.943 & 5 & 0.078 & 0.120 & \\
\hline Workforce quality & -0.252 & -1.246 & 5 & 0.078 & 0.126 & \multirow{2}{*}{ Missing } \\
\hline Long term orientation & -0.782 & 0.499 & 3 & 0.078 & 0.137 \\
& & & & & & \\
\hline
\end{tabular}

\section{Second: truth the measurement tool search}

Reliability is used to measure the consistency of the paragraphs of the questionnaire and the consistency of the results that are reached at different time periods, so the researchers employed for this aspect the Alpha-Cronbach scale, as its value requires that it be greater than (70\%) in order to be statistically accepted in administrative and behavioral research ( Nunnaly \& Bernstein, 1994), and Table (2) shows the variables searched and their dimensions in the research questionnaire their acceptability, and from the researcher's resort to splitting the research questionnaire into two halves as in Table (2), the first part is devoted to individual paragraphs (25) paragraphs, and the second of them (25) A paragraph after deleting the confirmatory factor analysis of five items $(10,17,19,28,55)$ as a result of the test's significance being greater than the level of significance (0.05), and in order to identify the correlation coefficient between the two halves of the questionnaire, the first part of it obtained a reliability coefficient (0.931). And through (25) paragraphs, the second part got a stability coefficient (0.903) through (25) paragraphs, so that the correlation coefficient of the partial resolution was (0.807) strong, in addition to Spearman Brown's coefficient (0.893), and the Cutman coefficient of half-segmentation (0.882), Thus, the two researchers adopt the questionnaire in its final form for statistical analysis. 
Table (2) Stability of the search scale by the half segmentation method

\begin{tabular}{|c|c|c|c|}
\hline Dimensions & $\begin{array}{l}\text { Number of } \\
\text { paragraphs }\end{array}$ & Stability coefficient $(\alpha)$ & Sample volume \\
\hline Individual paragraphs & 25 & 0.931 & 304 \\
\hline Marital paragraphs & 25 & 0.903 & \\
\hline $\begin{array}{l}\text { The correlation coefficient } \\
\text { of half-resolution }\end{array}$ & & 0.807 & \\
\hline Spearman Brown Labs & & 0.893 & \\
\hline $\begin{array}{l}\text { Cottman's modulus of half } \\
\text { segmentation }\end{array}$ & & 0.882 & \\
\hline
\end{tabular}

\section{Third: To present and analyze the results according to the sample answers}

Test the first main hypothesis of the research, which is concerned with verifying the correlation relationship between the two main research variables, and it was as follows (There is a significant correlation between the protean career path and its As Table (3) shows positive correlations, according to the following: dimensions with high performance and its dimensions) 
Table (3) Matrix of correlation between protean career path and high performance

\begin{tabular}{|c|c|c|c|}
\hline Variables & Values driven & Self-direction & $\begin{array}{l}\text { The protean } \\
\text { career path }\end{array}$ \\
\hline \multirow{3}{*}{$\begin{array}{l}\text { continuous } \\
\text { improvement }\end{array}$} & $0.598 * *$ & $0.649 * *$ & $0.698 * *$ \\
\hline & 0.000 & 0.000 & 0.000 \\
\hline & 304 & 304 & 304 \\
\hline \multirow{3}{*}{$\begin{array}{l}\text { Openness and work } \\
\text { orientation }\end{array}$} & $0.515 * *$ & $0.668^{* *}$ & $0.665 * *$ \\
\hline & 0.000 & 0.000 & 0.000 \\
\hline & 304 & 304 & 304 \\
\hline \multirow{3}{*}{$\begin{array}{l}\text { Management } \\
\text { quality }\end{array}$} & 0.568 & 0.601 & 0.655 \\
\hline & 0.000 & 0.000 & 0.000 \\
\hline & 304 & 304 & 304 \\
\hline \multirow[t]{3}{*}{ workforce quality } & $0.561^{* *}$ & $0.642 * *$ & $0.675 * *$ \\
\hline & 0.000 & 0.000 & 0.000 \\
\hline & 304 & 304 & 304 \\
\hline \multirow[t]{3}{*}{ Long term trend } & 0.130 * & 0.171 ** & $0.170^{* *}$ \\
\hline & 0.023 & 0.003 & 0.003 \\
\hline & 304 & 304 & 304 \\
\hline \multirow[t]{3}{*}{ High performance } & $0.609 * *$ & $0.704^{* *}$ & $0.737 * \star$ \\
\hline & 0.000 & 0.000 & 0.000 \\
\hline & 304 & 304 & 304 \\
\hline
\end{tabular}

$\mathrm{P} *<0.05, \mathrm{P} * *<0.01, \mathrm{P} * * *<0.001$

In order to test the first main hypothesis according to the results of Table (3), the protean career path achieved six significant direct correlations with high performance and its five dimensions. The interest of the researched scientific colleges in the protean career path of their teaching faculties as one unit interest will necessarily lead to an increase in automatic interest in high performance at the macro level and strongly, but at the level of dimensions, the increased interest of the researched faculties may lead to the protean career path, it will lead to increased interest in improvement. The continuous correlation with the same strong direct correlation coefficient $(0.698 * *)$ between them, at the level of significance (0.000), while the direct correlation relationship of the protean career path with the quality of the workforce in the third order and with a positive direct correlation coefficient $(0.675 * *)$ was strong at the level of significance $(0.000$ In the fourth order, the relationship with the subordinate dimension was openness and orientation towards work $(0.665$ **), strong at the level of morale (0.000), and in the fifth order, the protean career path showed an order relationship Positive (0.655) coefficients at the level of significance (0.000) with the quality of management, and finally the trend in values was associated with the long-term trend with a positive correlation $(0.170 * *)$ and weak at the level of significance 
(0.003), as the researchers note that all the values of the correlation coefficients With a level of significance less than the level of significance (0.05), and therefore accepting the first major research hypothesis (there is a significant correlation relationship between the protean career path and its dimensions with high performance and its dimensions).

2- Test the second main hypothesis (the presence of a significant effect of the protean career path and its dimensions in high performance), and to verify whether the hypothesis is accepted, or not, the simple and multiple linear regression model was implemented in a (Backward) method, in addition to the scheduled (T) value indicators (1.96) ), And the tabular (f) value (3.841) at the level of significance (0.05) for rejecting and accepting hypotheses, for the main hypothesis as follows:

From the results of Table (4), the researcher notes that there is an effect (of the protean career path) overall on (high performance), at the level of significance ( $\mathrm{sig}=0.000)$ - which is less than the value of the significance level $(0.05)$, and in terms of the value of $(\mathrm{F})$ calculated $(358,413))$, Which is greater than its tabular value (3.841), while the calculated (T) test value (18.932) for the value of () the standard beta margin (effect), which is greater than its scheduled value (1.96) at the same level of significance (0.05), Note that the value of the Durbin-Watson test reached (2.265), which is an acceptable value indicating the absence of a self-correlation between the independent variable and the dependent variable, and from all of the above, the third main hypothesis is accepted (the presence of a significant effect of the proteancareer path and its dimensions in high performance).

As a whole, the protean career path is explained by $(54.3 \%)$ of the changes that occur in high performance, while the remaining percentage of the model $(45.7 \%)$ is attributed to other variables that were not included in the tested research model, as this result indicates the interdependence of removing the volatile career path. More than if it affects individually, while the percentage of the proteancareer path effect was $(73.7 \%)$ in high performance, while the constant value was (1.124) and the calculated value of (T) was (7.438), that is, when the value of the marginal tendency is equal to zero, or The value of the proteancareer path is zero, so the value for high performance is (1.124), and as shown by the simple predictive linear regression equation:

High performance $(Y)=1.124+0.737 *($ proteancareer path $)$

Table (4) The effect of the protean career path and its dimensions on high performance $(n=304)$

\begin{tabular}{|c|c|c|c|c|c|c|c|}
\hline \multirow{2}{*}{$\begin{array}{r}\text { Independent } \\
\text { variable }\end{array}$} & \multicolumn{6}{|c|}{ High performance } & \multirow[b]{2}{*}{$\mathbf{F}$} \\
\hline & $\alpha$ & $\beta$ & $\mathbf{R}^{2}$ & Sig & $\mathrm{T}$ & D.W & \\
\hline values driven & 1.755 & 0.609 & 0.371 & 0.000 & 13.354 & 2.364 & 178.333 \\
\hline Self-direction & 1.648 & 0.704 & 0.496 & 0.000 & 17.238 & 2.002 & 297.154 \\
\hline $\begin{array}{r}\text { protean career } \\
\text { path }\end{array}$ & 1.124 & 0.737 & 0.543 & 0.000 & 18.932 & 2.265 & 358.413 \\
\hline \multicolumn{5}{|l|}{ Degree of freedom } & \multicolumn{2}{|c|}{302} & 303 \\
\hline
\end{tabular}

Then the researchers resorted to multiple regression in a (backward) manner, with the aim of identifying any dimensions of the protean career path represented by (values orientation and self-direction) an impact on high performance, and as shown by the results of Table (5), the effect of self-direction was to the forefront, with the value of the standard marginal tendency ( 0.529) and with a significant level (0.000) which is less than the level of significance (0.050), and with the calculated value of (T) (10.980), in addition to the effect of the trend in values, with a standard marginal slope (0.293), 
with a significant level (0.000), and with the calculated value (T) 6.079) which is greater than its tabular value (1.96), while the model correlation coefficient was (0.742), the value of the multiple regression coefficient $(0.551)$, the value of (F) computed for the model (184.743), and the value of the modified interpretation coefficient (0.548), which indicates that the two dimensions Values orientation and self-direction explain the rate $(54.8 \%)$ of the changes that occur to high performance in the three scientific colleges of the University of Baghdad, noting that the value of the test $(\mathrm{DW}=2.197)$, while the value of the constant was (1.165), at the level of significance (0.000), And with the calculated value of (T) (7.716).

Table (5) the multiple impact of the protean career path dimensions on high performance

\begin{tabular}{|c|c|c|c|c|c|c|c|}
\hline sample & & T value & $\begin{array}{l}\text { Standard } \\
\text { error }\end{array}$ & $\begin{array}{l}\text { Impact } \\
\text { factor }\end{array}$ & $\begin{array}{l}\text { The } \\
\text { Independent }\end{array}$ & & Dependent \\
\hline \multirow{2}{*}{$\begin{array}{c}\text { High } \\
\text { performance }\end{array}$} & $<--$ & values driven & 0.293 & 0.044 & 6.079 & 0.000 & \\
\hline & $<--$ & $\begin{array}{c}\text { Self- } \\
\text { direction }\end{array}$ & 0.529 & 0.041 & 10.980 & 0.000 & \\
\hline $\mathbf{F}$ & & Sig & \multicolumn{2}{|c|}{$\alpha$} & $\mathbf{R}$ & $\mathbf{R}^{2}$ & $\mathbf{A R}^{2}$ \\
\hline 184.743 & & 0.000 & \multicolumn{2}{|c|}{1.165} & .585 & .551 & .548 \\
\hline \multicolumn{3}{|c|}{ D.W (2.197) } & \multicolumn{2}{|c|}{$T=7.716$} & \multicolumn{3}{|c|}{$\mathrm{DF}(2,302,303)$} \\
\hline
\end{tabular}

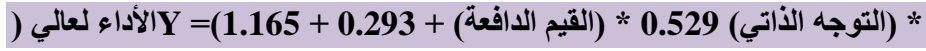

\section{CONCLUSIONS AND RECOMMENDATIONS}

\section{First: Conclusions}

1. The possibility of raising the level of high performance of the teachers was found through adopting individuals who have protean career paths, which is confirmed by the good moral correlation between them, and at the level of dimensions the best of these relationships between values orientation and high performance.

2. The protean career path affects high performance directly, as well as the effect of its dimensions of selfdirection and value-orientation on high performance and ranking.

3. A relative decline was found for most of the dimensions of high performance in the level of importance of the researched faculties, which indicates a relative application in achieving high performance in the researched faculties.
4. Members of the study sample in the researched colleges confirm the hypothesis that the protean career path contributes to making the faculty functional performance outputs (attitude and behavioral) more robust. Making their job outputs at work more powerful and contributing at the individual level, which means the possibility of reliance and reliance on them in measurement and deduction, based on the significance of the correlations between these variables.

\section{Second: Recommendations}

1. Investing more in the reciprocal correlation relationship between the protean career path and high performance, directly and indirectly, in a way that enhances the outputs of the faculties in quantity and quality and achieving excellence in performance by attracting and encouraging individuals with a protean career path and encouraging them and supporting them financially and morally to achieve psychological excellence. 
2. The researched colleges can work with the practices of high performance work systems because collecting and arranging these practices together leads to achieving greater performance outputs, whether at the level of the organization or at the individual level by focusing on the five dimensions mentioned in this research and investing more in them and applying them. .

3. It is necessary for the administration in the colleges to focus the sample of the study on the limitations and limitations that prevent the application or implementation of the practices of high performance work systems because they contribute significantly to achieving the advantage of human resources in them, according to the contemporary administrative trends that came in harmony with the results of the current study.

4. The necessity for the colleges to focus the study sample on the importance of providing a state of security, safety, and transfer for teachers through career path opportunities and make them feel the need to adhere to them and give them advancement in the career path by focusing on objective and subjective factors and provide career path opportunities for growth and advancement within colleges by motivating workers and encouraging them to show Their skills and abilities

\section{REFERENCES}

1- Alotaibi,Eqab Aiyadh \& Yusoff, Rushami Zien \& AlSharqi,Omar Zayyan \& Al-Matari,Ebrahim Mohammed,(2015),"Relationship between High Performance Work System and Patient Safety: Study on Saudi Arabia Public Hospitals", International Journal of Business and Management; Vol. (10), No. (1),PP.(115-123)

2- $\quad$ Briscoe, Jon P., Hall Douglas T., (2006), The interplay of boundaryless and protean careers: Combinations and implications, Journal of Vocational Behavior 69.

3- $\quad$ Cao, Lan\& et al, (2013), The positive effects of a protean Career attitudes for self-initiate expatriates, Career development international, vol (18), vol (1).

4- De Waal, A. A., Goedegebuure, R., \& Tan Akaraborworn, C. (2014). Adapting the high performance organization framework to the Thai context. Measuring Business Excellence, 18(2), 28-38.

5- De Waal, A., \& Chachage, B. (2011). Applicability of the high-performance organization framework at an East African university: The case of Iringa University College. International Journal of Emerging Markets, 6(2), 148167.

6- $\quad$ De Waal, A., \& Mulimbika, T. (2017). A comparative analysis of Zambian governmental institutions using the (HPO) framework. SAGE Open, 7(3), 1-17.

7- $\quad$ De Waal, A., \& Sultan, S. (2012). Applicability of the high performance organization framework in the Middle East: The case of Palestine Polytechnic University. Education, Business and Society: Contemporary Middle Eastern Issues, 5(3), 213-223.

8- De Waal, A., Andre, (2008), "The Secret of High Performance Organizations", European School of Management, Management Oline Review.

9- $\quad$ De Waal. (2010). Achieving High Performance in the Public Sector. Public Performance \& Management Review, 34(April), 81-103.

10- DiRenzo, M. S., \& Greenhaus, J. H. (2011). Job search and voluntary turnover in a boundaryless world: a control theory perspective. Academy of Management Review, 36(3).

11- Douglas T. Hall, (2004), the protean career: A quarter-century journey, Journal of Vocational Behavior 65.

12- $\quad$ Enache, Mihaela \& others, (2012), Protean and boundaryless career attitudes scale, Intangible capital journal, Vol (8), No (1).

13- Gubler, M., Arnold, J. and Coombs, C. (2014), "Reassessing the protean career concept: empirical findings, conceptual components, and measurement”, Journal of Organizational Behavior,Vol. 35.

14- Haber, A., \& Bertone, A. (2016). Protean career model. The Encyclopedia of Adulthood and Aging, John Wiley \& Sons, Inc. 
15- Hall, D.T. and Chandler, D.E. (2005), "Psychological success: when the career is calling", Journal of Organizational Behavior, Vol. 26.

16- King, Z. (2004), "Career self-management: its nature, causes and consequences", Journal of Vocational Behavior, Vol. 65 No. 1, pp. 112-133.

17- Kopelman, S., Feldman, E. R., McDaniel, D. M., \& Hall, D. T. T. (2012). Mindfully negotiating a career with a heart. Organizational Dynamics, 41.

18- $\quad$ Mcgregor, B., (1999), "Public Service Status Review the Excellence Agend", Public Administration, Vol. 54, No. 3, pp. 296-301.

19- Nunnally, J.C. and Bernstein, I.H. (1994) The Assessment of Reliability. Psychometric Theory, 3, $248-292$.

20- Sirén, C., Thorgren, S., \& Järlström, M. (2018). Self-directed career exploration: A comparison of CHOICES and the Self-Directed Search. Journal of Vocational Behavior, 20(1), 22-30.

21- Sultana R and Malik OF, (2019), Is Protean Career Attitude Beneficial for Both Employees and Organizations? Investigating the Mediating Effects of Knowing Career Competencies. Front. Psychol. 